\title{
Adsorption of Chromium(Vi) from Aqueous Solution by Glycine Modified Cross-linked Chitosan Resin
}

\author{
Asmaa S. Hamouda ${ }^{1}$, Sayed A. Ahmed ${ }^{1}$, Nahla M. Mohamed ${ }^{1}$, Mostafa M.H. \\ Khali $^{*}$ \\ ${ }^{1}$ Faculty of Postgraduate Studies of Advanced Sciences (PSAS), Beni Suef University, \\ Beni Suef, Egypt. \\ ${ }^{2}$ Chemistry Department, Faculty of Science, Ain Shams University, Abbassia, 11566, \\ Cairo, Egypt.
}

\begin{abstract}
$\mathbf{T}$ HE ADSORPTION of Cr(VI) onto glycine-modified crosslinked chitosan (GMCCR) resin has been investigated. Batch experiments were performed to examine kinetics, adsorption isotherm, $\mathrm{pH}$ effect, and thermodynamic parameters. The effect of $\mathrm{pH}$ for the adsorption of $\mathrm{Cr}(\mathrm{VI})$ was studied at range from 2 to 6 and the equilibrium was accomplished within 150 minutes and maximum removal was achieved under the optimum conditions at $\mathrm{pH} 3$. The result obtained from equilibrium adsorption studies are fitted Langmuir and Freundlich adsorption models and the data was found that the equilibrium data agreed very well with the Langmuir model. The maximum uptake was found to be $1.5 \mathrm{mmol} / \mathrm{g}$ (calc $1.75 \mathrm{mmol} / \mathrm{g}$ ) at $250 \mathrm{C}$. Thermodynamic parameters for the adsorption system were determined at $298 \mathrm{~K}$, $308 \mathrm{~K}$ and $318 \mathrm{~K}\left(\Delta \mathrm{H}^{\circ}=22.85 \mathrm{~kJ} \bullet \mathrm{mol}-1 ; \Delta \mathrm{G}^{\circ}=-33.17\right.$ to $-36.93 \mathrm{~kJ} \bullet \mathrm{mol}-1$ and $\Delta \mathrm{S}^{\circ}=188$ $\mathrm{J} \cdot \mathrm{K}-1 \cdot \mathrm{mol}-1)$. The positive values of $\Delta \mathrm{H}^{\circ}$ and $\Delta \mathrm{S}^{\circ}$ suggest an endothermic reaction and increase in randomness at the solid-liquid interface during the adsorption. The negative values of $\Delta \mathrm{G}^{\circ}$ indicating a spontaneous adsorption process. The kinetic process was described very well by a pseudo-second-order rate equation.
\end{abstract}

Keywords: Modified chitosan, Adsorption, Kinetics, Thermodynamics, Cr(VI).

\section{Introduction}

Chromium occurs mainly in the oxidation states trivalent $\mathrm{Cr}$ (III) and hexavalent in the environment $\mathrm{Cr}(\mathrm{VI})$ state. Whereas $\mathrm{Cr}(\mathrm{III})$ is essential in human nutrition (specially in glucose metabolism) as well as for plants and animals at trace concentrations, the hexavalent $\mathrm{Cr}(\mathrm{VI})$ has been considered more hazardous to public health due to its mutagenic and carcinogenic properties [1]. It is also moving readily through soils and aquatic environments and is a strong oxidizing agent capable of being absorbed through the skin [2]. A wide range of physical and chemical processes is available for the removal of $\mathrm{Cr}(\mathrm{VI})$ from drinking water, such as electrochemical precipitation, ultrafiltration, reverse osmosis and ion exchange [3-5]. Most of these methods suffer from high operational costs. Therefore, it is necessary to develop new treatment processes that are not only effective, but also feasible in terms of cost [6-8]. Adsorption is one of the most economically favorable and a technically easy method [9].

Chitosan has been reported to have high potential for adsorption of chromium(VI) [10,11]. It is an amino-polysaccharide constituted of both acetylglucosamine and glycosamine moieties. Chitosan has been widely applied to the fields of pharmacy processing biotechnology, food and analytical chemistry. Amino group and hydroxyl group in chitosan exhibit good ability to chelate metal ions. On the other side, chitosan represents suitable materials for binding of metal oxo-anion species because of numerous functional groups (e.g., $-\mathrm{OH}$ and -NH2) with their suitable H-bond acceptor and donor sites. Adsorption capacity of chitosan can be improved by chemical means such as addition of functional groups, crosslinking and by physical conditioning of the biopolymer as gel beads or fibers [12-14]. Several chemical changes have been applied to chitosan in order to enhance 
its uptake of Cr (VI) from the solution [15-19]. Novel chitosan resins possessing chelating moieties have been developed by using acrosslinked chitosan resin as a base material. The development of chelating resin is important from the viewpoint of the collection and separation of metal ions [20]. The cross-linked chitosan is found to be very stable and maintain their strength even in acidic and basic solutions. These characteristics are very important for an adsorbent so that it can be used in a lower $\mathrm{pH}$ environment [21].

In the present work, we prepared modified glutaraldehyde-crosslinked chitosan glycinetype and used it to adsorb $\mathrm{Cr}$ (VI) ions in a batch system. The effects of the process parameters such as $\mathrm{pH}$, temperature on the removal were investigated. In order to have better understanding of the adsorption process, some isotherm, kinetic and thermodynamic models were employed.

\section{Experimental}

\section{Chemicals}

Chitosan (from crab shell), glycine, glutaraldehyde, isopropyl alcohol, epichlorohydren, $\mathrm{K}_{2} \mathrm{Cr}_{2} \mathrm{O}_{7}$ were Aldrich products. All other chemicals were Prolabo products and were used as received.

Preparation of glycine modified chitosan resin

The glutaraldehyde-crosslinked chitosan glycine type was prepared as in literature [22]. Three grams of chitosan was dissolved in $20 \%$ aqueous solution of acetic acid and stirred until the solution became homogenous. Then $1 \mathrm{~mL}$ of glutaraldehyde solution (50\%) was added and the solution was stirred with heating for two hours. The $\mathrm{pH}$ of the solution was raised to 6 and the obtained gel was washed with distilled water several times and kept to dry. The obtained crosslinked chitosan gel from the previous step was suspended in $60 \mathrm{~mL}$ isopropyl alcohol. Then $7 \mathrm{~mL}$ epichlorohydrine $(62.5 \mathrm{mmol})$ dissolved in $100 \mathrm{~mL}$ acetone/water mixture $(1: 1 \mathrm{v} / \mathrm{v})$ was added. The above mixture was stirred for $24 \mathrm{~h}$ at $60{ }^{\circ} \mathrm{C}$. The obtained solid product was filtered off and washed several times with water followed by ethanol. The product and glycine $(10 \mathrm{~g})$ were suspended in dioxane $(100 \mathrm{ml})$, then $40 \mathrm{ml} \mathrm{NaOH}$ (1M) was added and the mixture was refluxed for $3 \mathrm{~h}$. the final product was filtered and washed 3 times with ethanol and with deionized water. The synthesis steps are shown in Scheme 1.

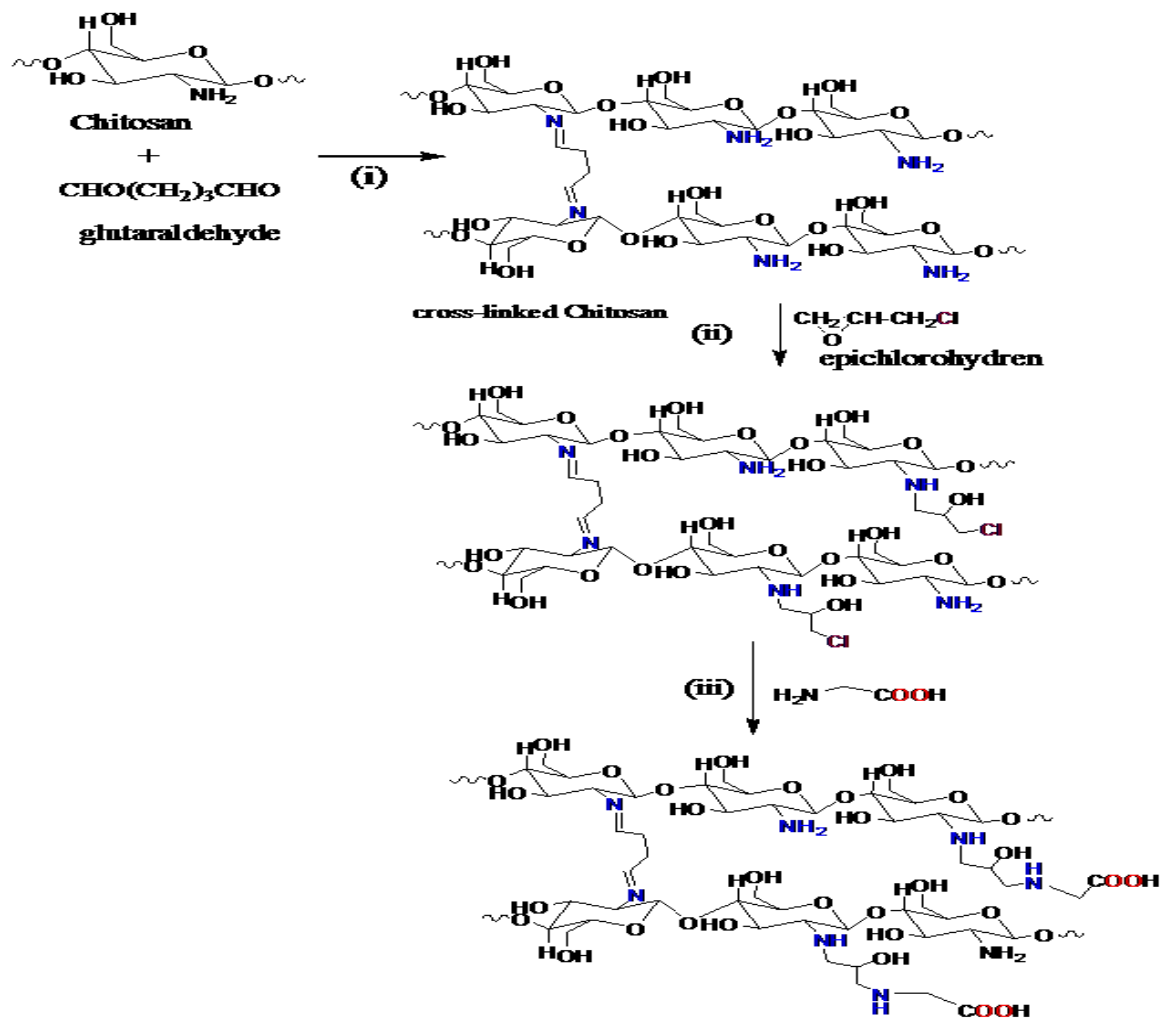

glycine-modified chitosan resin

Scheme 1

Egypt. J. Chem. 61, No.5 (2018) 


\section{Characterization of the resin}

Infrared spectra were performed using Nicolet 6700 FT-IR Spectrometer. The surface morphology of the absorbent was visualized with a scanning electron microscope (JEOL-1200, Japan). The scanning electron microscopy (SEM) enabled us to direct observation of the changes in the surface microstructures of the absorbent. X-ray diffraction (XRD, JCPDS No. 03-0921) was used to characterize the crystal structures of chitosan and GMCCR.

\section{Water Regain}

For water regain determination, resin sample was centrifuged for $30 \mathrm{~min}$ at $1000 \mathrm{rpm}$ to remove excess water and then weighed. The sample was then dried at $50-60{ }^{\circ} \mathrm{C}$ until complete dryness then weighed again. To calculate this factor, the

$$
W \%=\frac{\left(W_{w}-W_{d}\right) 100}{W_{W}}
$$

Where $W_{w}$ and $W_{d}$ are weights (g) of the wet and dried resin, respectively. Water regain values are $(37 \pm 3 \%)$. This value reflects the hydrophilic character of the resin type.

\section{Uptake experiments using batch method \\ Preparation of solutions}

Stock solution $\left(1 \times 10^{-2} \mathrm{M}\right)$ of chromium (VI) was prepared by dissolving $1.47 \mathrm{~g} \mathrm{~K}_{2} \mathrm{Cr}_{2} \mathrm{O}_{7}$ in $1 \mathrm{~L}$ bi-distilled water. All batch experiments were carried out with adsorbent samples in a $250 \mathrm{~mL}$ conical flasks with $100 \mathrm{~mL} \mathrm{Cr}$ (VI) aqueous solutions on a rotary shaker at $200 \mathrm{rpm}$. The concentration of $\mathrm{Cr}(\mathrm{VI})$ ions was determined spectrophotometrically at $540 \mathrm{~nm}$ using diphenylcarbazide as the complexing agent.

\section{Effect of $p H$}

The uptake of $\mathrm{Cr}$ (VI) by the investigated resins was studied at different $\mathrm{pH}$ values from 2 to 6 . The $\mathrm{pH}$ was adjusted using $\mathrm{HCl}$ or $\mathrm{NaOH}$. $0.1 \mathrm{~g}$ of investigated resin was placed in a series of flasks. To each flask $100 \mathrm{~mL}$ of Cr (VI) solution $\left(5 \times 10^{-3} \mathrm{M}\right)$ was added. The contents of each flask were shaken for $150 \mathrm{~min}$ on a shaker at $200 \mathrm{rpm}$ and at temperature $20 \pm 1{ }^{\circ} \mathrm{C}$ at desired $\mathrm{pH}$. The resin was separated from the solution by filtration. Then the residual concentration of $\mathrm{Cr}$ (VI )was determined.

\section{Adsorption isotherms}

Complete adsorption isotherms were carried out by placing $0.1 \mathrm{~g}$ portions of dried resin in a series of flasks containing $100 \mathrm{~mL}$ of $\mathrm{Cr}$ (VI) ions at $\mathrm{pH}$. The temperature was thermostatically kept at $25 \pm 1,35 \pm 1$ or $45 \pm 1^{\circ} \mathrm{C}$ and equilibrium time 150 min for studied resin. The residual concentration of $\mathrm{Cr}$ (VI) was determined. The adsorption data were treated according to Langmuir equation [23].

$$
\mathrm{q}_{\mathrm{e}}=\frac{\mathrm{Q}_{\max } \mathrm{K}_{\mathrm{L}} \mathrm{C}_{\mathrm{e}}}{1+\mathrm{K}_{\mathrm{L}} \mathrm{C}_{\mathrm{e}}}
$$

Where qe the adsorbed value of $\mathrm{Cr}$ (VI) ions at equilibrium concentration $(\mathrm{mmol} / \mathrm{g}), \mathrm{Q}_{\max }$ is the maximum adsorption capacity $(\mathrm{mmol} / \mathrm{g})$ and $\mathrm{K}_{\mathrm{L}}$ is the Langmuir binding constant which is related to the energy of adsorption ( $\mathrm{L} / \mathrm{mmol}), \mathrm{C}_{\mathrm{e}}$ is the equilibrium concentration of $\mathrm{Cr}$ (VI) in solution $(\mathrm{mmol} / \mathrm{L})$.

Its linearized equation is shown as below

$$
\frac{\mathrm{C}_{\mathrm{e}}}{\mathrm{qe}_{\mathrm{e}}}=\frac{\mathrm{C}_{\mathrm{e}}}{\mathrm{Q}_{\max }}+\frac{1}{K_{L} \mathrm{Q}_{\max }}
$$

Plotting Ce/qe against Ce gives a straight line with slope and intercept equal to $1 / \mathrm{Q}_{\max }$ and $1 / \mathrm{K}_{\mathrm{L}} \mathrm{Q}_{\max }$, respectively. The essential characteristics of the Langmuir isotherm can be expressed in terms of a dimensionless constant separation factor $\mathrm{R}_{\mathrm{L}}$ that is given by

$$
R_{L}=\frac{1}{1+K_{\mathrm{L}} \mathrm{C}_{\mathrm{i}}}
$$

Where $C \mathrm{i}(\mathrm{mmol} / \mathrm{L})$ is the highest initial concentration of adsorbate and $\mathrm{R}_{\mathrm{L}}$ values $0<\mathrm{R}_{\mathrm{L}}<$ 1 imply favorable adsorption. The Freundlich empirical relationship describes the multilayer adsorption of heterogeneous systems and assumes that different sites have several adsorption energies involved [18]. The linear model of the isotherm can be expressed logarithmically as

$\log q_{e}=\log K_{F}+\frac{1}{n} \log C_{e}$

Where, $K$ and $1 / n$ are Freundlich constants. The values of $\mathrm{K}$ and $1 / n$, which roughly correspond to the adsorption capacity and the heterogeneity factor.

The thermodynamic parameters of adsorption reaction were obtained from the treatment of KL values at different temperature according to van't Hoff equation [24].

$\ln K_{\mathrm{L}}=\frac{-\Delta \mathrm{H}^{\circ}}{\mathrm{RT}}+\frac{\Delta \mathrm{S}^{\circ}}{\mathrm{R}}$

where $\Delta \mathrm{H}^{\circ}$ and $\Delta \mathrm{S}^{\circ}$ are enthalpy and entropy changes, $\mathrm{R}$ is the universal gas constant (8.314 
$\mathrm{J} / \mathrm{mol} . \mathrm{K}$ ) and $\mathrm{T}$ is the absolute temperature (K). Plotting $\ln \mathrm{K}_{\mathrm{L}}$ against $1 / \mathrm{T}$ gives a straight line with slope and intercept equal to $-\Delta H^{\circ} / \mathrm{R}$ and $\Delta \mathrm{S}^{\circ} / \mathrm{R}$, respectively. The Gibbs free energy of adsorption $\left(\Delta G^{\circ}\right)$ at different temperatures was calculated using the following relation:

$\Delta \mathbf{G}^{\mathbf{0}}=\Delta \mathbf{H}^{\mathbf{0}}-\mathbf{T} \Delta \mathbf{S}^{\mathbf{0}}$

Effect of contact time on the uptake

The effect of contacting time on the uptake of $\mathrm{Cr}$ (VI) by resins was carried out by placing 0.1 $\mathrm{g}$ of dry resin in a flask containing $100 \mathrm{~mL}$ of $\mathrm{Cr}$ (VI) solution at initial concentration of $5 \times 10^{-3} \mathrm{M}$ and $\mathrm{pH} 3$. The contents of the flask were placed on a shaker at $200 \mathrm{rpm}$ and at temperature $20 \pm 1$ ${ }^{\circ} \mathrm{C}$. Five milliliters of the solution were taken at different time intervals and used to determine the residual concentration of $\mathrm{Cr}(\mathrm{VI})$. The adsorption data were treated according to the kinetic models,

\section{Desorption experiments}

For desorption studies, $0.15 \mathrm{~g}$ of GMCCR was loaded with metal ions using $\mathrm{Cr}$ (VI) solution $\left(5 \times 10^{-3} \mathrm{M}\right)$ solution at $25{ }^{\circ} \mathrm{C}, \mathrm{pH} 3$ and contact time of $150 \mathrm{~min}$, on a shaker at $200 \mathrm{rpm}$. After adsorption the GMCCR adsorbed with $\mathrm{Cr}$ (VI) ions were separated from the solution by filtration and then added into $30 \mathrm{~mL} 0.15 \mathrm{~N} \mathrm{NaOH}$ and stirred at $250 \mathrm{rpm}$ for $30 \mathrm{~min}$ at $25^{\circ} \mathrm{C}$ and the final $\mathrm{Cr}$ (VI) concentration was determined.

The adsorption-desorption cycles were repeated consecutively five times to determine the reusability of sorbents. After each cycle of adsorption-desorption, sorbent was washed with distilled water and used in the succeeding cycle. The desorption ratio of $\mathrm{Cr}(\mathrm{VI})$ ions from GMCCR was calculated from the amount of $\mathrm{Cr}$ (VI) ions adsorbed on GMCCR and the final Cr (VI) ions concentration in the medium. Desorption ratio was calculated from the following equation:

$$
\text { Desorption ratio }=\frac{\text { amount of Cr (VI) ions desorbed to the medium }}{\text { amount of } \mathrm{Cr}(\mathrm{VI}) \text { ions adsorbed onto the GMCCR }} \times 100
$$

\section{Results and Discussions}

\section{FTIR and SEM analysis}

To confirm the synthesis route of the glucinechitosn crosslinked resin, FT-IR spectroscopy was used to determine the main characteristic functional groups on the adsorbent. The FTIR spectrum of chitosan powder is shown in Fig.1(a). A broad peak centered at $3420 \mathrm{~cm}^{-1}$ was attributed to $\mathrm{O}-\mathrm{H}$ and $\mathrm{N}-\mathrm{H}$ stretching vibrations and the peak at $2882.9 \mathrm{~cm}^{-1}$ due to $-\mathrm{CH}$ stretching vibration in $-\mathrm{CH}$, and $-\mathrm{CH} 2$. The FTIR of chitosan showed bands that can be assigned as: $1650 \mathrm{~cm}^{-1}$ (-NH bending vibration in -NH2), $1424 \mathrm{~cm}^{-1}(-\mathrm{NH}$ deformation vibration in -NH2), $1154 \mathrm{~cm}^{-1}(-\mathrm{CN}$ stretching vibration), 1061.4 and $1031 \mathrm{~cm}^{-1}$ (-CO stretching vibration in $-\mathrm{COH})$, and $897.6 \mathrm{~cm}^{-1}$ (-CN stretching vibration [25]. The FTIR spectrum of the (GMCCR) is presented in Fig. 1(b). After

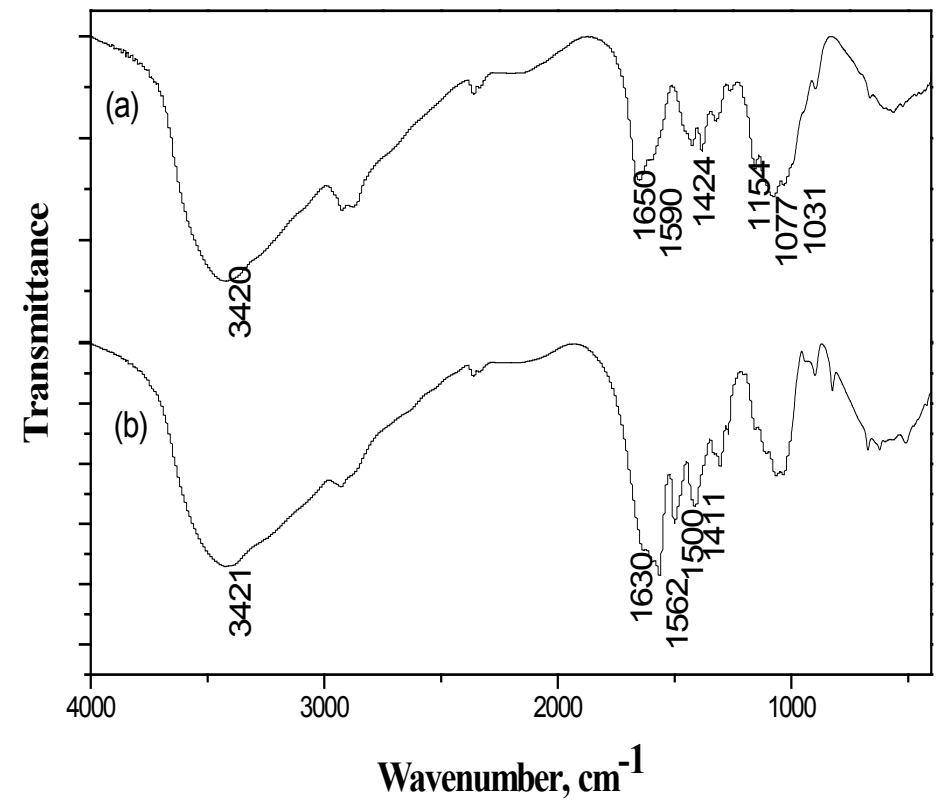

Fig. 1. FTIR of a) chitosan and b) glycine modified chosen resin(GMCCR). 

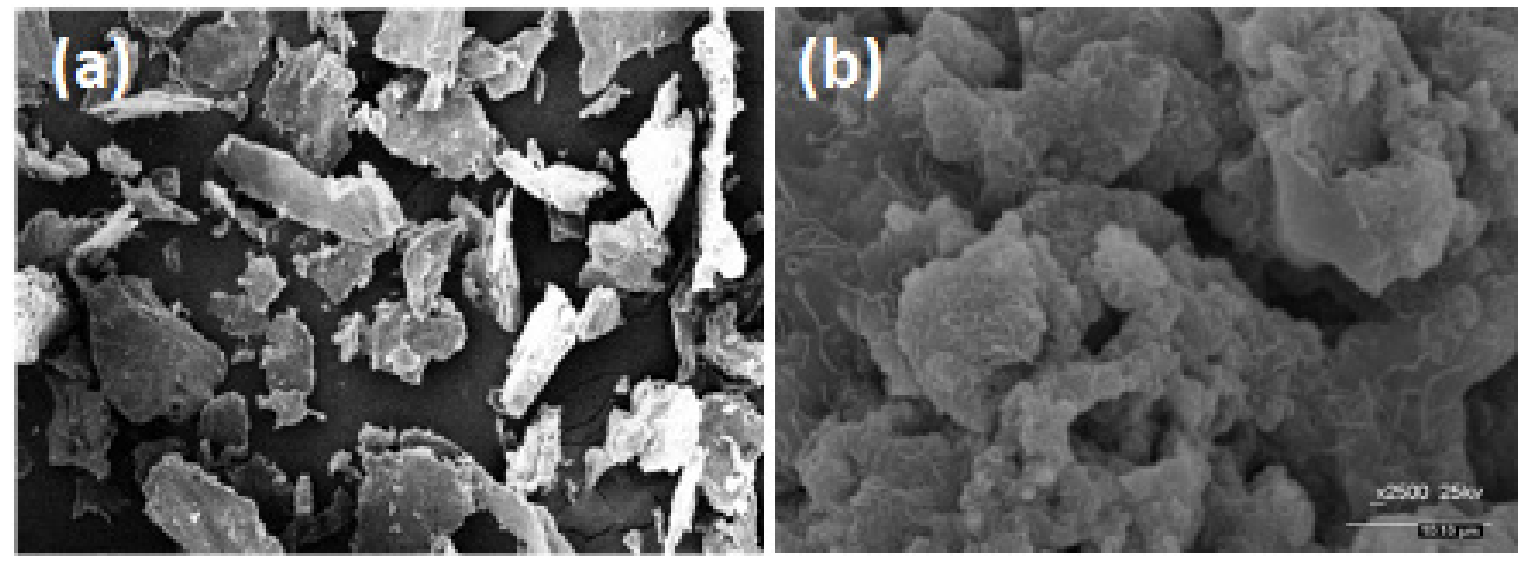

Fig. 2. SEM micrographs of a) chitosan and b) GMCCR resin (the surface morphology)

chitosan was crosslinked, an important peak in this region appeared at $1630 \mathrm{~cm}^{-1}$; it was attributed to the imine $-\mathrm{C}=\mathrm{N}$ - band ) [26]. Meanwhile, The peak at $1562 \mathrm{~cm}^{-1}$ can be assigned to the $\mathrm{C}=\mathrm{N}-$ stretching vibration, indicating that some of the -NH2 groups were changed into the $\mathrm{C}=\mathrm{N}$ - groups, and the new band at $1500 \mathrm{~cm}^{-1}$ and at $1424 \mathrm{~cm}^{-1}$ can be assigned to $\delta_{\mathrm{s}} \mathrm{NH}_{3}^{+}$and COO- (stretching vibrations from glycine).

Figure 2 shows the SEM micrographs of the chitosan and GMCCR resin. It can be seen from Fig. 1(a) that the chitosan particles were mostly irregular in shape and had loose surfaces. After they were crosslinked GMCCR becomes regular in shape and had dense surfaces and become rigid comparing to raw chitosan make it easier to separate from the solution (Fig. 1b). This result is in agreement with Huang et al [27].

Figure 3 shows the XRD patterns of chitosan and the GMCCR resin. In the chitosan XRD pattern, the peaks appeared at $11^{\circ}$ and $20.1^{\circ}$ correspond to a mixture of (lllll $\left.\begin{array}{lll}0 & 1\end{array}\right)$ and $\left(\begin{array}{lll}0 & 0 & 2\end{array}\right)$, and $\left(\begin{array}{lll}0 & 0 & 1\end{array}\right)$ and (1 00 ), respectively [28]. GMCCR exhibited the smaller characteristic peak of crystallinity than original chitosan, and it is clear that the crystallinity decreases after cross-linking using glutaraldehyde due to the Schiff's base

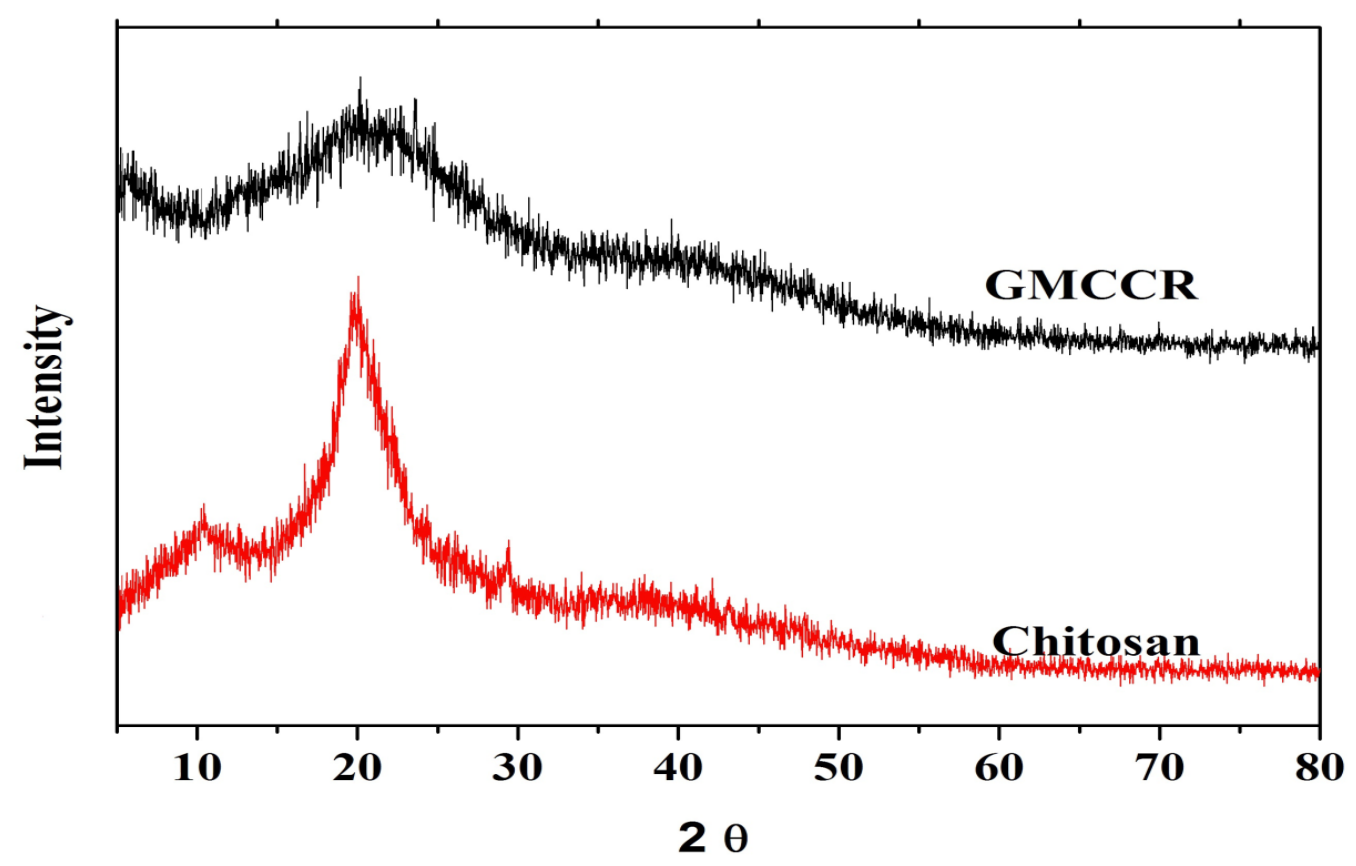

Fig. 3. The XRD spectrum of chitosan and GMCCR resin 
TABLE 1. Langmuir constants for adsorption of Cr (VI) on Chitosan-Glycine resin.

\begin{tabular}{|c|c|c|c|c|c|c|c|}
\hline & \multicolumn{2}{|c|}{$\begin{array}{c}\text { Langmuir } \\
\text { constants }\end{array}$} & \multicolumn{5}{c|}{ Freundlich constants } \\
\cline { 2 - 7 }$(\mathbf{K})$ & $\begin{array}{c}\mathbf{Q}_{\text {max, exp }} \\
(\mathbf{m m o l} / \mathbf{g})\end{array}$ & $\begin{array}{c}\mathbf{Q}_{\text {max, calc }} \\
(\mathbf{m m o l} / \mathbf{g})\end{array}$ & $\begin{array}{c}\mathbf{K}_{\mathbf{L}} \\
(\mathbf{L} / \mathbf{m m o l})\end{array}$ & $\mathbf{R}^{2}$ & $\mathbf{1} / \mathbf{n}$ & $\mathbf{K}_{\mathrm{f}}$ & $\mathbf{R}^{2}$ \\
\hline 298 & 1.5 & 1.75 & 697 & 0.996 & 0.244 & 4.83 & 0.938 \\
\hline 308 & 1.85 & 1.91 & 1025 & 0.997 & 0.215 & 5.17 & 0.996 \\
\hline 318 & 2.10 & 2.31 & 1241 & 0.994 & 0.199 & 5.83 & 0.994 \\
\hline
\end{tabular}

TABLE 2. Enthalpy, entropy and free energy changes for adsorption of $\mathrm{Cr}$ (VI) ions on Chitosan-Glycine resin.

\begin{tabular}{|c|c|c|c|c|c|c|}
\hline \multirow{2}{*}{$\left(\mathbf{H}^{\mathbf{0}} \mathbf{( k J} / \mathbf{m o l} \Delta\right.$} & \multirow{2}{*}{$\left(\mathbf{S}^{\mathbf{0}} \mathbf{( J / m o l . K} \Delta\right.$} & & & & \\
\cline { 3 - 6 } & & \multicolumn{2}{|c|}{ Temperature, $\mathbf{K}$} & \multicolumn{2}{|c|}{$\Delta \mathbf{G}^{\mathbf{0}}(\mathbf{k J} / \mathbf{m o l})$} & \multicolumn{2}{|c|}{$\mathbf{T} \mathbf{\Delta S}(\mathbf{k J} / \mathbf{m o l})$} \\
\hline 22.85 & 188 & 298 & -33.17 & 56.02 \\
\hline & & 308 & -35.05 & 57.90 \\
\hline & & 318 & -36.93 & \multicolumn{2}{|c|}{59.78} \\
\hline
\end{tabular}

formation between amino groups of chitosan and carbonyl groups of glutaraldehyde and subsequent reaction with glycine.

\section{Effect of pH on the uptake}

The $\mathrm{pH}$ is an important parameter for the adsorption process because of its influence on the adsorbent surface properties and ionic form of metal ion form in the solution. In acid medium, when the $\mathrm{pH}$ in the range of 2 to $6, \mathrm{HCO} 4-$ and $\mathrm{Cr}_{2} \mathrm{O}_{7}^{--}$are predominantly in equilibrium; in basic medium $\mathrm{Cr}(\mathrm{VI})$ exist in the $\mathrm{CrO}_{4}^{--}$form. The effect of $\mathrm{pH}$ on the uptake of $\mathrm{Cr}(\mathrm{VI})$ was studied at initial $\mathrm{pH}$ values of 2.0, 2.5, 3.0,3.5.4.0,5 and 6. The modified chitosan showed higher uptake capacity towards $\mathrm{Cr}(\mathrm{VI})$ was achieved at $\mathrm{pH} 3$, (Fig. 4). The important parameters for adsorption of metal ions are the concentration of the counter ions on the functional group of the adsorbent and the degree of ionization of the adsorbate during the reaction. The decrease in the uptake at $\mathrm{pH}<3$ could be attributed to the higher concentration of $\mathrm{Cl}^{-}$ions which compete the chromate anion. On the other hand, the decrease in the uptake value above $\mathrm{pH} 3$ can be due to the lower extent of protonation of amino group with raising $\mathrm{pH}$. The mechanism of interaction of chromate anion could be as anion exchange $\mathrm{RNH}_{2}^{+} \mathrm{Cl}^{-}+\mathrm{HCrO}_{4}^{-} \leftrightarrow \mathrm{RNH}_{2}^{+}$ $\mathrm{HCrO}_{4}^{-}+\mathrm{Cl}^{-}$in the acid medium. Then, $\mathrm{pH} 3$ was taken for the removal of $\mathrm{Cr}(\mathrm{VI})$ by GMCCR for further experiments. In alkaline conditions, it was found that the increasing $\mathrm{OH}^{-}$anion brought a competitive sorption with chromate anions

TABLE 3. Kinetic Parameters for the adsorption of $\mathrm{Cr}$ (VI) on the studied Chitosan-Glycine resin.

\begin{tabular}{|c|c|c|c|c|c|}
\hline \multicolumn{3}{|c|}{ Pseudo-First order } & \multicolumn{3}{|c|}{ Pseudo-Second order } \\
\hline $\begin{array}{c}k_{1} \\
\left(\mathrm{~min}^{-1}\right)\end{array}$ & $\begin{array}{c}\mathbf{q}_{\mathrm{e}, \text { calc }} \quad \mathrm{q}_{\text {exp }} \\
(\mathrm{mmol} / \mathrm{g})\end{array}$ & $\mathbf{R}^{2}$ & $\begin{array}{c}k_{2} \\
(\mathrm{~g} / \mathrm{mmol} \mathrm{min})\end{array}$ & $\begin{array}{c}\mathrm{q}_{\mathrm{e}, \text { calc }} \\
(\mathrm{mmol} / \mathrm{g})\end{array}$ & $\mathbf{R}^{2}$ \\
\hline 0.0191 & 1.54 & 0.986 & 0.012 & 1.88 & 0.997 \\
\hline
\end{tabular}


TABLE 4. Adsorption-desorption cycles for GMCCR. (Adsorption conditions: volume, $100 \mathrm{~mL}$; absorbent dose, $0.15 \mathrm{~g}$; initial concentration, $\left(5 \times 10^{-3} \mathrm{M}\right.$; $\mathrm{pH} \mathrm{3}$, contact time, $150 \mathrm{~min}$; temperature, $25{ }^{\circ} \mathrm{C}$; agitation speed, $200 \mathrm{rpm}$. Desorption conditions: $0.15 \mathrm{~N} \mathrm{NaOH}$; volume, $30 \mathrm{~mL}$; contact time, 30 min; temperature, $25^{\circ} \mathrm{C}$; agitation speed, $250 \mathrm{rpm}$.).

\begin{tabular}{ccc}
\hline Cycle number & adsorption & Desorption \\
\hline 1 & 100 & 92.5 \\
2 & 92.3 & 90.9 \\
3 & 89.8 & 85.1 \\
4 & 86.6 & 78.3 \\
5 & 82.5 & 76.4 \\
\hline
\end{tabular}

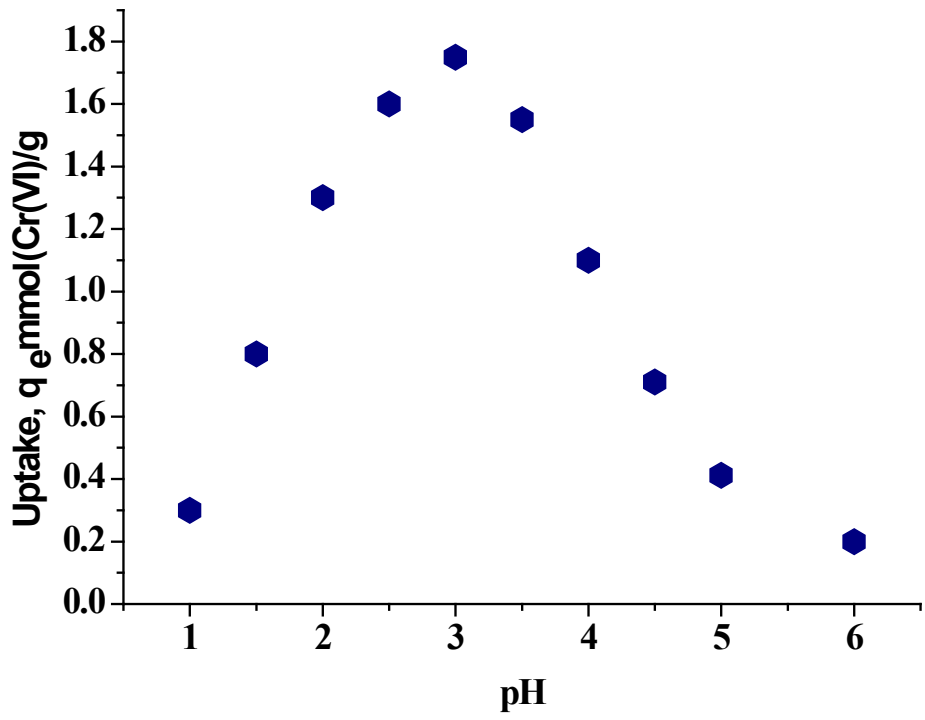

Fig. 4. Effect of $\mathrm{pH}$ on the uptake of $\mathrm{Cr}(\mathrm{VI})$ by Chitosan-Glycine resin at initial concentration of $5 \times 10^{-3} \mathrm{M}$ for; contact time $150 \mathrm{~min}$ at temperature $25^{\circ} \mathrm{C}$.

leading to decrease in the sorption capacity of the modified chitosan towards $\mathrm{Cr}(\mathrm{VI})$ ions [29].

\section{Adsorption isotherms}

Adsorption isotherms are commonly used to reflect the performance of adsorbents in adsorption processes. Figures 5 and 6 represented the adsorption isotherms of $\mathrm{Cr}$ (VI) by (GMCCR) at $\mathrm{pH} 3$ and at different temperatures using the Langmuir and Freundlich models, respectively. Both isotherms were fitted to experimental data, and the goodness of fit was compared. Isotherm parameters for the Langmuir and Freundlich models for the(GMCCR) are reported in Table 1. At $25^{\circ} \mathrm{C}$ the maximum uptakes for (GMCCR) are $1.5 \mathrm{mmol} / \mathrm{g}$, . The values of $\mathrm{K}_{\mathrm{L}}$ and $\mathrm{Q}_{\max }$ for adsorption of $\mathrm{Cr}(\mathrm{VI})$ on resin was calculated from Langmuir isotherm (Fig. 5b). The values of $\mathrm{Q}_{\max }$ are close to the experimental ones, and the values of $\mathrm{R}^{2}$ reported in Table 1, which is a measure of the goodness-of-fit, confirm the better representation of the experimental data by Langmuir model. This indicates the homogeneity of active sites on the resin surface and suggests that the adsorption of 

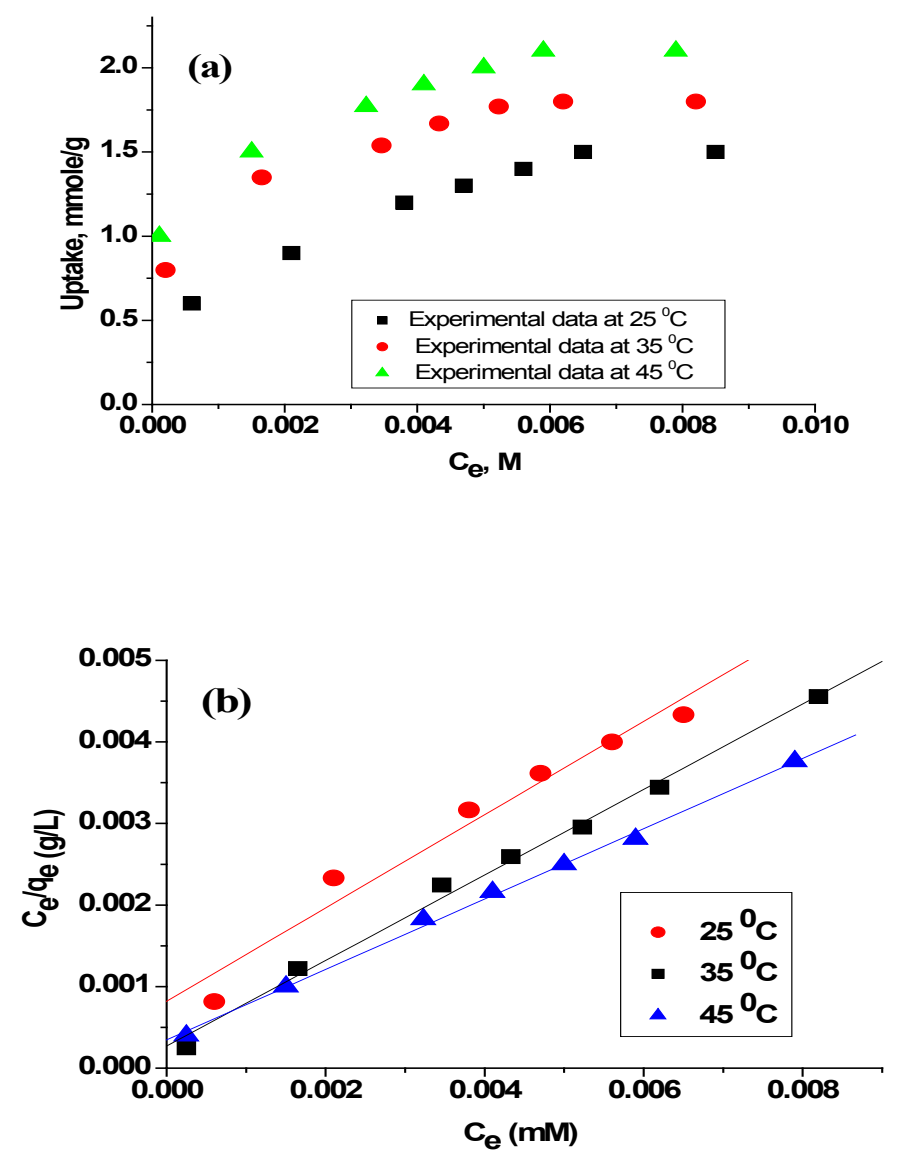

Fig. 5.a) Uptake Cr (VI) on (GMCCR) at different temperatures; pH 3; contact time $150 \mathrm{~min}$, b) Langmuir isotherm.isotherm.

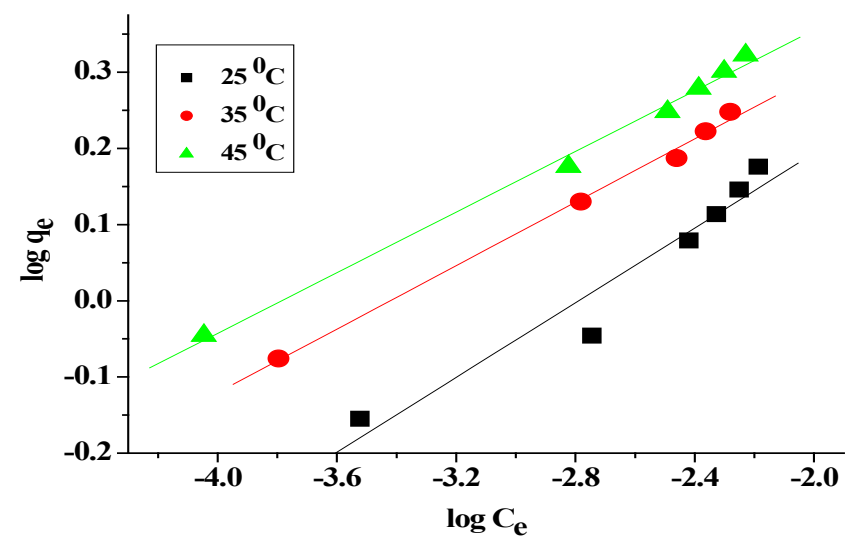

Fig. 6. Freundlich isotherms for the adsorption of $\mathrm{Cr}$ (VI) on (GMCCR) at different temperatures; pH 3; contact time $150 \mathrm{~min}$. 


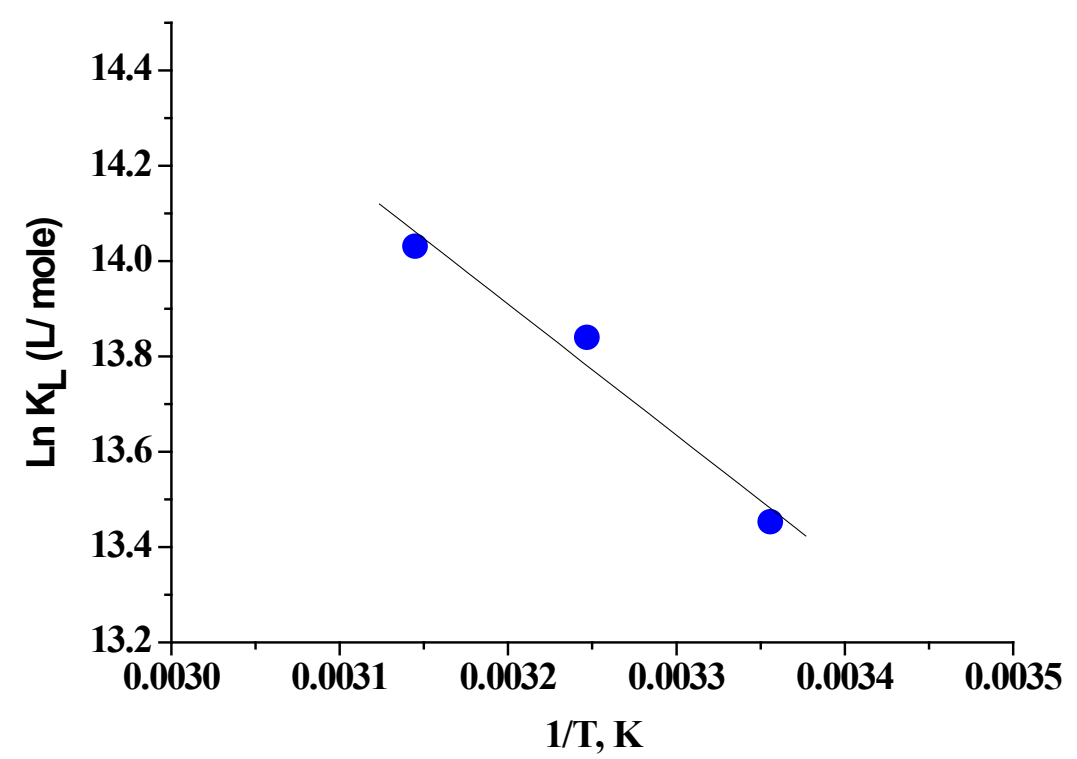

Fig. 7. Van't Hoff plots for adsorption of Cr (VI) on Chitosan-Glycine resin.

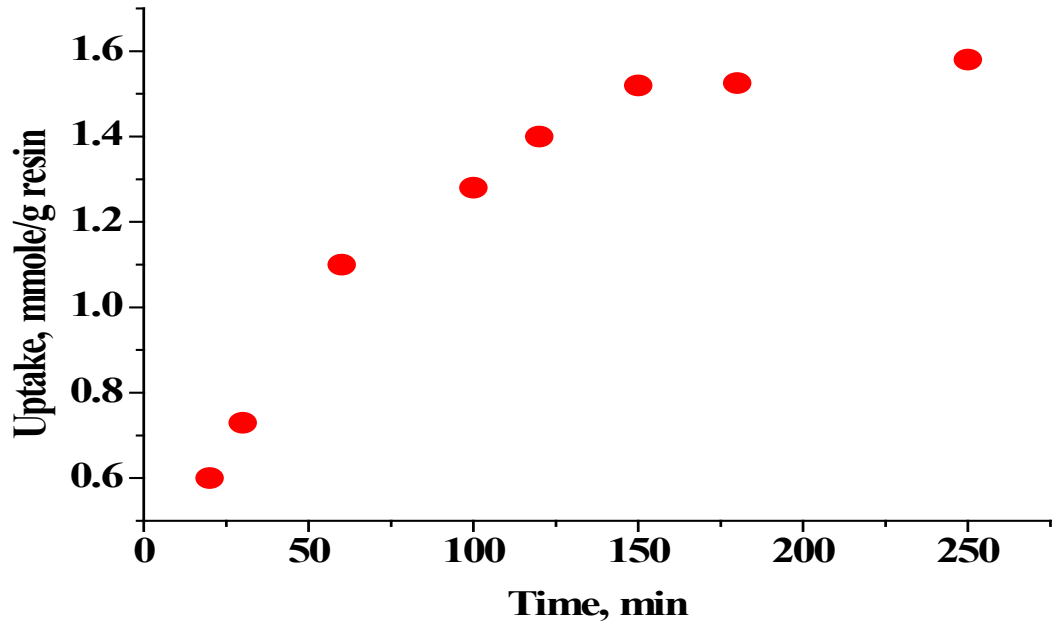

Fig. 8. Uptake of $\mathrm{Cr}$ (VI) by Chitosan-Glycine resin as a function of time at $25^{\circ} \mathrm{C}$; $\mathrm{pH} 3$; initial concentration of $5 \times 10^{-3} \mathrm{M}$.

$\mathrm{Cr}(\mathrm{VI})$ on chitosan or GMCCR mainly occurred by monolayer reaction. The value of $R_{L}$ in the present investigation was calculated to be 0.45 which indicates favorable adsorption of $\mathrm{Cr}(\mathrm{VI})$ on the resin.

Langmuir isotherm is found to be the applied isotherm for chitosan and modified chitosan by other authors [24, 30]. The observed increase of $Q_{\max }$ and $K_{\mathrm{L}}$ with increasing temperature for (GMCCR) may be related to the increase of the stability of the complex formed between $\mathrm{Cr}$ (VI) and protonated amino groups (at $\mathrm{pH} 3$ ) in the resin. The values of $\mathrm{K}_{\mathrm{L}}$ gives a good idea about the ability of the resin for removing $\mathrm{Cr}$ (VI) from low concentrations. The reported values of $\mathrm{K}_{\mathrm{L}}$ (Table 1) indicates the high removal efficiency of the resin for $\mathrm{Cr}$ (VI) from diluted solutions.

Egypt. J. Chem. 61, No.5 (2018) 

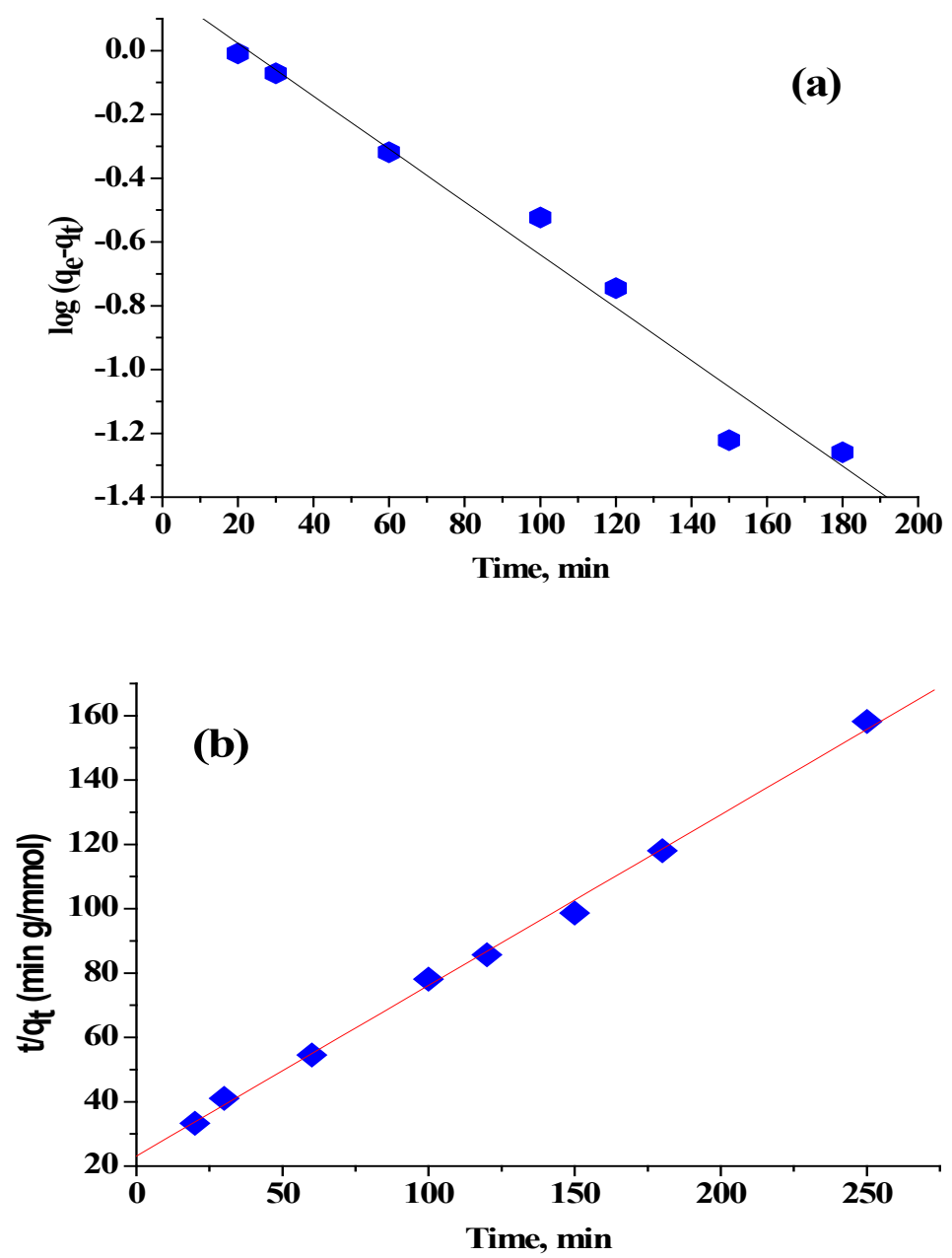

Fig. 9. (a) Pseudo first-orders and (b) Pseudo second-order kinetics of the uptake of Cr (VI) on (GMCCR) at $25^{\circ} \mathrm{C}$; pH 3; initial concentration of $5 \times 10^{-3} \mathrm{M}$.

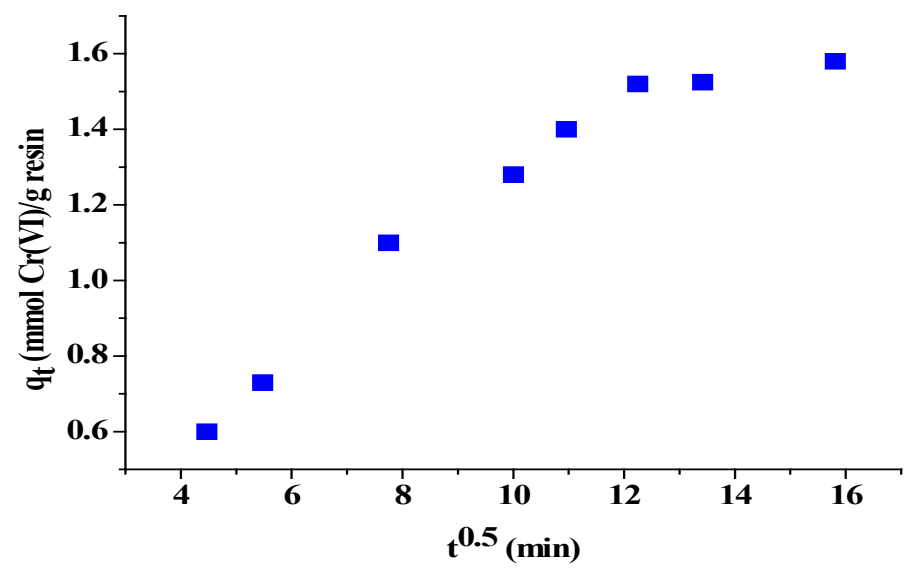

Fig. 10. The intraparticle diffusion kinetic model of the uptake of $\mathrm{Cr}$ (VI) by (GMCCR) 
The reported values of $\Delta \mathrm{H}^{\circ}, \Delta \mathrm{S}^{\circ}$ and $\Delta \mathrm{G}^{\circ}$ in Table 2 were calculated from Fig.7. The positive value of $\Delta \mathrm{H}^{\circ}$ indicates an endothermic adsorption process, and are coherent with chemical process, which confirms that the complex formation between $\mathrm{Cr}$ (VI) and amine sits on the resin surface. It is seen that the values of $\Delta \mathrm{G}^{\circ}$ decreases as the temperature increases. This implies that, the adsorption becomes more favorable at higher temperature [31]. The thermodynamic behavior may be attributed to the increased number of active sites as well as the endothermic nature of the reaction between resin active sites and $\mathrm{Cr}$ (VI) ions. This may also be reflected in the values of $\mathrm{K}_{\mathrm{L}}$. The values of $\mathrm{K}_{\mathrm{L}}$ increase as the temperature increases, indicating higher affinity of the resin towards $\mathrm{Cr}(\mathrm{VI})$ at higher temperature.

\section{Adsorption kinetics}

The adsorption of $\mathrm{Cr}$ (VI) on (GMCCR) resin as a function of time at $\mathrm{pH} 3$ and $25^{\circ} \mathrm{C}$ is shown in Fig. 8. Clearly, the equilibrium time was reached after approximately $150 \mathrm{~min}$. The data in Fig. 8 were treated according to pseudo-first (Fig. 9a) and pseudo-second order kinetic models (Fig. 9b).

The pseudo-first order is models are expressed as [32]

$q_{t}=q_{e}\left[1-\exp ^{-k_{1} t}\right]$

Its linearized equation is shown as below:

$\log \left(q_{e}-q_{t}\right)=\log q_{e}-\left(\frac{k_{1}}{2.303}\right) t$

where $\mathrm{k}_{1}$ is the pseudo first-order rate constant $\left(\mathrm{min}^{-1}\right)$ of adsorption and $\mathrm{q}_{\mathrm{e}}$ and $\mathrm{q}_{\mathrm{t}}(\mathrm{mmol} / \mathrm{g})$ are the amounts of $\mathrm{Cr}$ (VI) adsorbed at equilibrium and time $t$, respectively. The pseudo-second order model is expressed as [33]:

$q_{t}=\frac{k_{2} t}{1+k_{2} q_{e} t}$

Its liberalized equation is shown as below:

$$
\frac{\mathrm{t}}{\mathrm{q}_{\mathrm{t}}}=\frac{1}{\mathrm{k}_{2} \mathrm{q}_{\mathrm{e}}^{2}}+\left(\frac{1}{\mathrm{q}_{\mathrm{e}}}\right) \mathrm{t}
$$

where $\mathrm{k}_{2}$ is the pseudo second order rate constant of adsorption $\left(\mathrm{g} \mathrm{mmol} \mathrm{min}^{-1}\right)$. The kinetic parameters in both models are determined from the linear plots of $\log \left(q_{e}-q_{t}\right)$ vs $t$ for pseudo firstorder, (Fig. 9a) or $\left(\mathrm{t} / \mathrm{q}_{\mathrm{e}}\right)$ vs $\mathrm{t}$ for second order, (Fig.9b). The validity of each model is checked by the fitness of the straight line $\left(\mathrm{R}^{2}\right)$. The pseudo first-order and pseudo second-order rate constants as well as equilibrium sorption capacities were reported in Table 3. According to the data shown in Table 3, for (GMCCR) resin, and the consistency of the between the calculated value and experimental value of $\mathrm{q}_{\mathrm{e}}$, pseudo secondorder model is the more valid for the adsorption process than pseudo first-order one. This implies that the adsorption process proceeds according to pseudo second-order and depends upon both metal ion concentration and the textural properties of the resin. The intraparticle diffusion model indicated that the relationship between the concentration of $\mathrm{Cr}(\mathrm{VI})$ and the square root of time (Fickian diffusion law [24]; $\mathrm{q}_{\mathrm{t}}=\mathrm{K}_{\mathrm{i}} \mathrm{t}^{0.5}+\mathrm{X}$, ) is not linear, Fig.8. This implies that the overall rate of adsorption for the resin is controlled by intraparticle diffusion with the boundary layer diffusion [34]. When intraparticle diffusion alone is the rate limiting step, then the plot of $\mathrm{q}_{\mathrm{t}}$ versus $\mathrm{t}_{0.5}$ passes the origin. When film diffusion is also taking place then the intercept is $\mathrm{X}$, which gives an idea on the thickness of the boundary layer. From Fig. 8, it is evident that the adsorption process followed two steps. The first linear portion followed the boundary layer diffusion followed by another linear portion which represents the intraparticle diffusion [35].

\section{Desorption studies}

As shown in Table 4, the capacity of the GMCCR was an $7.7 \%$ decrease after the first cycle and a $11.2 \%$ decrease after the second cycle but it could still be maintained at $82.5 \%$ level at the fifth cycle. Complete desorption was not possible, perhaps due to the involvement of non-electrostatic forces between the GMCCR and the $\mathrm{Cr}$ (VI) ions. These results showed that the GMCCR can be successfully regenerated and repeatedly used in $\mathrm{Cr}$ (VI) ions adsorption studies without appreciable losses in their adsorption capacities.

\section{Conclusion}

The glycine-modified chitosan is found to have a maximum uptake of $\mathrm{Cr}(\mathrm{VI})$ of $1.5 \mathrm{mmol} / \mathrm{g}$ at $25{ }^{\circ} \mathrm{C}$. Sorption of chromium on modified chitosan was influenced by the $\mathrm{pH}$ of the medium. Chromium sorption follows Langmuir isotherm. The nature of sorption process is spontaneous and endothermic. The mechanism of chromium sorption on the modified chitosan is governed by electrostatic adsorption and complexation. Regeneration of cross-linked magnetic GMCCR 
obtained was achieved by using $0.15 \mathrm{M} \mathrm{NaOH}$ with efficiency of greater than $85 \%$. The glycine modified chitosan is stable and good for chromium sorption and could be used for field applications.

\section{References}

1. Basha S., Murthy Z.V.P., Jha B.. Biosorption of hexavalent chromium by chemically modified seaweed, Cystoseiraindica, Chem. Eng. J. 137, 480-488 (2008).

2. Park S., Jung W.Y. Removal of chromium by activated carbon fibers plated with copper metal, Carbon Sci. 2, 15-21 (2001).

3. Rengaraj S., Yeon K.H., Moon S.H. Removal of chromium from water and wastewater by ion exchange resins, J. Hazard. Mater. 87, 273-287 (2001).

4. Benito Y., Ruiz M.L. Reverse osmosis applied to metal finishing wastewater, Desalination, 142, 229-234 (2002)

5. Yurlova L., Kryvoruchko A. Removal of $\mathrm{Ni}$ (II) ions from wastewater by micellarenhanced ultrafiltration, Desalination, 144, 255-260 (2002).

6. Sharma C.D., Forster F.C. Removal of hexavalent chromium using sphagnum moss peat, Wat. Res. 27, 1201 (1993)

7. Bailey S.E., Olin T.J., Bricka R.M., Adrian D.D. A review of potentially low-cost sorbents for heavy metals, Wat. Res. 33, 2469 (1999).

8. Babel S., Kurniawan T.A. Low-cost adsorbents for heavy metals uptake from contaminated water: a review, J. Hazard. Mater. B 97, 219 (2003).

9. Karthikeyan T., Rajgopal S., Miranda L.R. Chromium (VI) adsorption from aqueous solution by Hevea Brasilinesis sawdust activated carbon, J. Hazard. Mater. B124, 192-199 (2005)

10. Modrzejewska, Z., Sujka, W., Dorabialska, M., Zarzycki, R. Adsorption of $\mathrm{Cr}(\mathrm{VI})$ on Cross-linked Chitosan Beads. Sep. Sci. Technol., 41, 111-122 (2006).

11. Zarzycki, R., Sujka, W., Dorabialska, M., Modrzejewska, Z. Adsorption of $\mathrm{Cr}(\mathrm{VI})$ on Chitosan Beads. Chem. Inz. Ekol. 9, 15611570 (2002).
12. Alves N.M., Mano J.F. Chitosan derivatives obtained by chemical modifications for biomedical and environmental applications, Int. J. Biol. Macromol. 43, 401-414 (2008).

13. Rojas G., Silva J., Flores J.A., Rodriguez A., Adsorption of chromium onto crosslinked chitosan, Sep. Purif. Technol. 44, 31-36 (2005)

14. Khalil, M. M. H Atrees M. S., Abd El Fatah A. I. L., Salem H.\& Roshdi R. Synthesis and application studies of chitosan acryloylthiourea derivative for the separation of rare earth elements, Journal of Dispersion Science and Technology, 39(4), 605-613 (2018).

15. Rajiv Gandhi, M., Meenakshi, S. Preparation and characterization of $\mathrm{La}$ (III) encapsulated silica gel/chitosan composite and its metal uptake studies, J. Hazard. Mater., 203-204, 29-37 (2012).

16. Karthik, R., Meenakshi, S. Removal of hexavalent chromium ions from aqueous solution using chitosan/polypyrrole composite, Desalin. Water Treat., 52, 1-14 (2014).

17. Rajiv Gandhi M., Viswanathan, N., Meenakshi, S. Preparation and application of alumina/chitosan biocomposite, Int. J. Biol. Macromol., 47, 146-154 (2010).

18. Kousalya, G.N., Gandhi, M., Meenakshi, S. Sorption of chromium(VI) using modified forms of chitosan beads, Int. J. Biol. Macromol., 47, 308-315(2010).

19. Hua C., Zhang R., Bai F., Lu P., Liang X., Removal of chromium (VI) from aqueous solutions using quaternized chitosan microspheres, Chinese J. Chem. Eng. (2016), doi:10.1016/j.cjche.2016.08.024

20. Elwakeel K.Z., Removal of $\mathrm{Cr}(\mathrm{VI})$ from alkaline aqueous solutions using chemically modified magnetic chitosan resins, Desalination, 250, 105-112 (2010).

21. Chiou M.S. and Li H.Y. Adsorption behavior of reactive dye in aqueous solution on chemical cross-linked chitosan beads, Chemosphere, 50, 1095 (2003).

22. Khalil M.M.H., Al-Wakeel K. Z., Abd El Rehim S. S., Abd El Monem H. Efficient 
removal of ferric ions from aqueous medium by amine modified chitosan J. Environm. Chem. Engineering 1, 566-573 (2013).

23. Langmuir, The adsorption of gases on plane surfaces of glass, mica and platinum, J. Am. Chem. Soc. 40, 1361-1403 (1918).

24. Elwakeel K.Z., Abd El-Ghaffar M.A., ElKosy S.M., El-Shorbagy H.G. Enhanced remediation of Reactive Black 5 from aqueous media using new chitosan ion exchangers, J. Dispersion Sci. Technol. 34, 1008-1019 (2013).

25. Pentrák M., Pentrákova L., Radian A., Mishael Y. G., and Stucki J. W. Nitrate reduction by redox-modified smectites exchanged with chitosan. Clays Clay Miner. 62, 403-414 (2014).

26. Li N., Bai R.A. Novel Amine-Shielded Surface Cross-Linking of Chitosan Hydrogel Beads for Enhanced Metal Adsorption Performance, Ind. Eng. Chem. Res. 44, 66926700 (2005).

27. Huang R., Yang B., Liu Q. Removal of Chromium(VI) Ions from Aqueous Solutions with Protonated Crosslinked Chitosan, J. Appl. Polym. Sci. (2013) DOI: 10.1002/ APP.38685.

28. Abou El-Reash, Y. G., Otto, M., Kenawy, I. M., \& Ouf, A. M. Adsorption of Cr(VI)and $\mathrm{As}(\mathrm{V})$ ions by modified magnetic chitosan chelating resin. International Journal of Biological Macromolecules, 49, 513-522
(2011).

29. Song W., Shi T., Yang D., Ye J., Zhou Y., Feng Y. Pretreatment effects on the sorption of $\mathrm{Cr}(\mathrm{VI})$ onto surfactant modified zeolite: mechanism analysis. J Environ Manag.162, 96-101 (2015).

30. Pang M., Kano N.,Imaizumi H. Adsorption of Chromium (VI) from Aqueous Solution Using Zeolite/Chitosan Hybrid Composite, J. Chem. Chem. Eng. 9, 433-441 (2015).

31. Jassal P.S., Raut V.P. and Anand N., Removal of Chromium (VI) ions from Aqueous solution onto Chitosan and Cross-linked Chitosan Beads, Proc Indian Nat. Sci Acad. 76, 1-6 (2010).

32. Lagergren S., About the theory of so-called adsorption of soluble substances. Kungliga Svenska Vet 24, 1-39 (1898).

33. Ho Y.S., McKay G., Pseudo-second order model for sorption processes, Process Biochem. 34, 451-465 (1999).

34. Donia A.M., Atia A.A., Heniesh A.M., Efficient removal of $\mathrm{Hg}$ (II) using magnetic chelating resin derived from copolymerization of bisthiourea/thiourea/ glutaraldehyde, Sep. Purif. Technol. 60, 46-53 (2008).

35. Vasanth Kumar K., Ramamurthi V., Sivanesan $\mathrm{S}$. Modeling the mechanism involved during the sorption of methylene blue onto fly ash. J. Colloid Interface Sci. 284, 14-21 (2005).

(Received 26/2/2018; accepted 10/7/2018) 


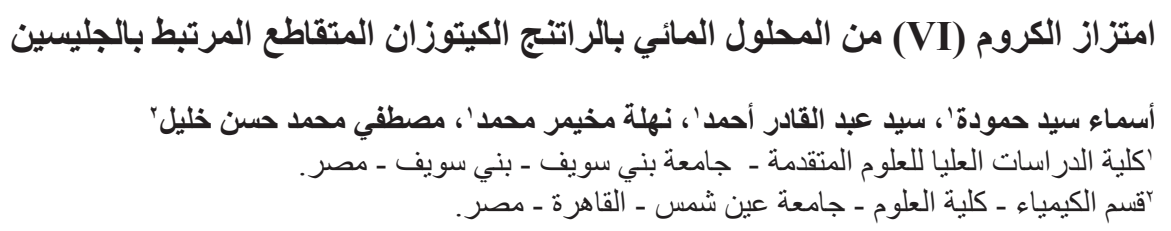

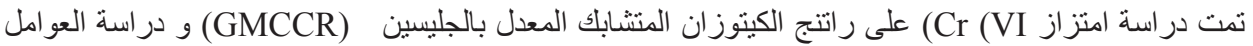

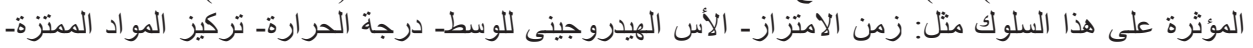

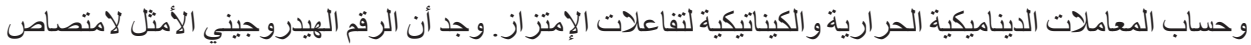
(Cr (VI

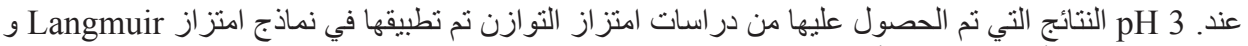

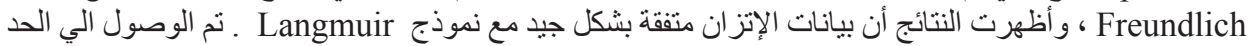

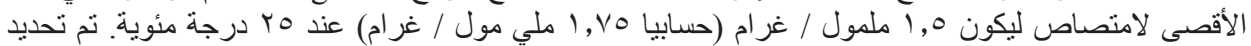

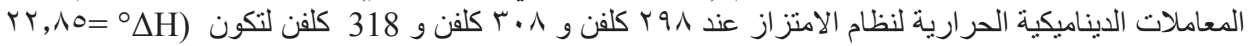

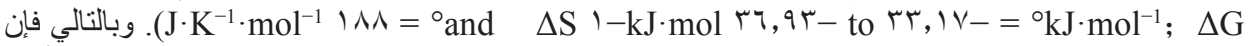
القيم الإيجابية لكل من عل

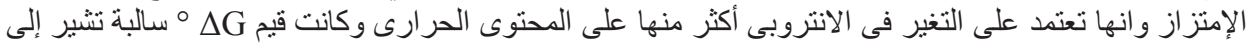

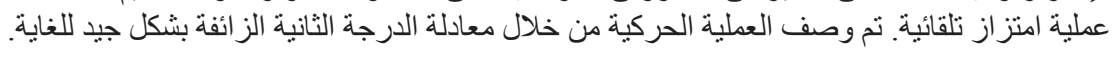

